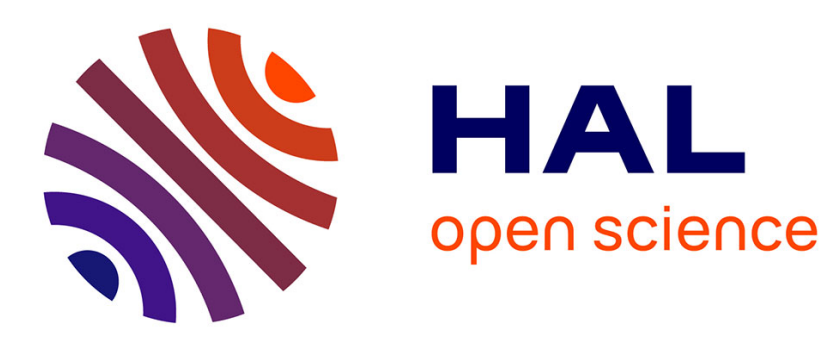

\title{
Structuring of self-assembled three-dimensional photonic crystals by electron-beam lithography
}

Patrick Ferrand, M. Egen, R. Zentel, J. Seekamp, S. G. Romanov, C. M. Sotomayor Torres

\section{- To cite this version:}

Patrick Ferrand, M. Egen, R. Zentel, J. Seekamp, S. G. Romanov, et al.. Structuring of self-assembled three-dimensional photonic crystals by electron-beam lithography. Applied Physics Letters, 2003, 83 (25), pp.5289-5291. 10.1063/1.1636271 . hal-00272373

\section{HAL Id: hal-00272373 https://hal.science/hal-00272373}

Submitted on 15 Apr 2015

HAL is a multi-disciplinary open access archive for the deposit and dissemination of scientific research documents, whether they are published or not. The documents may come from teaching and research institutions in France or abroad, or from public or private research centers.
L'archive ouverte pluridisciplinaire HAL, est destinée au dépôt et à la diffusion de documents scientifiques de niveau recherche, publiés ou non, émanant des établissements d'enseignement et de recherche français ou étrangers, des laboratoires publics ou privés. 


\title{
Structuring of self-assembled three-dimensional photonic crystals by direct electron-beam lithography
}

\author{
P. Ferrand ${ }^{\text {a) }}$ \\ Institute of Materials Science and Department of Electrical and Information Engineering, \\ University of Wuppertal, Gaußstraße 20, D-42097 Wuppertal, Germany \\ M. Egen and R. Zentel \\ Institute for Organic Chemistry, Department of Chemistry and Pharmacy, University of Mainz, \\ Duesbergerweg 10-14, D-55099 Mainz, Germany \\ J. Seekamp, S. G. Romanov, and C. M. Sotomayor Torres \\ Institute of Materials Science and Department of Electrical and Information Engineering, \\ University of Wuppertal, Gaußstraße 20, D-42097 Wuppertal, Germany
}

(Received 11 August 2003; accepted 31 October 2003)

\begin{abstract}
An electron-beam lithography technique is described capable of structuring three-dimensional self-assembled photonic crystals. It is shown that the control of the writing depth can be achieved by varying the electron acceleration voltage. Microscopic structures with a depth from 0.4 up to 2 $\mu \mathrm{m}$ are fabricated with a typical lateral resolution of $0.4 \mu \mathrm{m}$. The relevance of this technique for the fabrication of deterministic defects sites in opal photonic crystals is discussed and its extension towards buried structures is suggested. (C) 2003 American Institute of Physics.
\end{abstract}

[DOI: $10.1063 / 1.1636271]$

Periodic refractive index materials allow the manipulation of photons in analogy to the manipulation of electrons by the periodic potential of semiconductors. ${ }^{1}$ Due to the potential to control light emission, routing, and filtering, these photonic crystals (PhCs) constitute a promising approach towards a future generation of optoelectronic devices, combining high integration and high-speed processing. In this context, research on self-assembled PhCs (e.g., opals), gained much attention since this approach allows the realization of genuine three-dimensional (3D) $\mathrm{PhCs}^{2}$ It is probably the only approach able to provide a full control of light emission and propagation, with submicron feature sizes required by optical wavelengths. Compared to competing techniques involving micromanipulation ${ }^{3}$ or layer-by-layer growth, ${ }^{4}$ selfassembly is significantly more cost effective and compatible with very-large-scale integration technologies.

With the crystal growth established, the next step is to explore fabrication techniques to fashion, assemble, and structure these $\mathrm{PhCs}$, in order to build complex architectures. Dramatic progress has been achieved recently by using deep structured silicon substrates as a container, in order to grow high-quality $\mathrm{PhCs}$ of controlled size and shape on a technology-relevant platform. ${ }^{5,6}$ Furthermore, it is desirable to create intentional microscopic defects, to provide light confinement and guiding. Indeed, these structures constitute the building blocks of light circuits, and they are expected to benefit from reduced losses when they are embedded within a $3 \mathrm{D} \mathrm{PhC}{ }^{7}$ The introduction of a small proportion of spheres of different size during the crystallization has been recently proposed as a possible way towards this goal. ${ }^{8}$ Nevertheless the positioning of such defect remains to be controlled. A

a) Present address: Institut Fresnel, CNRS UMR 6133, Domaine Universitaire de Saint Jérôme, F-13397 Marseille Cedex 20, France; electronic mail: patrick.ferrand@fresnel.fr method using two-photon polymerization has been demonstrated, ${ }^{9}$ but the volume of the smallest structure is limited by optical diffraction to $\lambda^{3}$, where $\lambda$ is the laser wavelength. ${ }^{10}$ In this letter, we describe a technique which allows fabrication of deterministic structures in 3D PhCs using direct electron-beam lithography (EBL).

Colloidal monodisperse poly(methyl methacrylate) (PMMA) microspheres were synthesized via surfactant-free emulsion polymerization, using the routine described elsewhere. ${ }^{11}$ The polymer colloids had the measured molecular weight of $200000 \mathrm{~g} / \mathrm{mol}$ with a measured polydispersity index of 2.4. The (100) silicon substrates were cleaned by a standard process, hydrophilized in a $\mathrm{H}_{2} \mathrm{O}_{2}(35 \%): \mathrm{NH}_{3}(25 \%): \mathrm{H}_{2} \mathrm{O}(1: 1: 5)$ bath for $3 \mathrm{~h}$ and rinsed in deionized water. The sedimentation was performed by drawing up the substrate in a vertical position ${ }^{12}$ at a velocity of about $300 \mathrm{~nm} / \mathrm{s}$ from a $3 \mathrm{wt} \%$ suspension of spheres of diameter 325 or $400 \mathrm{~nm}$. With these parameters, the opal films were about $10 \mu \mathrm{m}$ thick. All these processes were carried out at ambient conditions. Sintering was performed at $80^{\circ} \mathrm{C}$ for $2 \mathrm{~h}$ in air. EBL was carried out using a Philips XL30-SFEG scanning electron microscope (SEM) equipped with a Raith Elphy Plus EBL control unit at accelerating voltages $V_{\text {acc }}$ between 2 and $30 \mathrm{kV}$ and a free working distance of $5 \mathrm{~mm}$. The exposure dose was $400 \mu \mathrm{C} / \mathrm{cm}^{2}$. Fine tuning of the beam focusing, writing location, and orientation was possible by a preliminary $5 \mathrm{~s}$ scan of the whole writing field for imaging, with a dose lower than $100 \mathrm{nC} / \mathrm{cm}^{2}$, which is insufficient to expose the material. After exposure, the samples were developed for $20 \mathrm{~s}$ in a solution of methyl isobutyl ketone (MIBK) and then placed in a solution of isopropanol to stop the development process for $20 \mathrm{~s}$. The samples were dried in a flow of nitrogen. Prior to imaging with a Philips XL30-TMP SEM, the samples were sputtered with a $10 \mathrm{~nm}$ thin film of gold. 


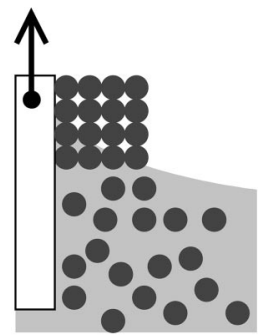

(a) growth

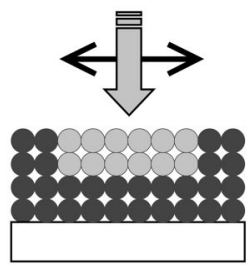

(c) exposure

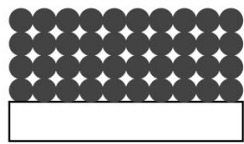

(b) sintering

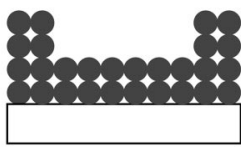

(d) after developing
FIG. 1. Scheme of the complete process, from opal growth to defect generation by direct EBL.

EBL is a standard lithography technique widely used to create two-dimensional patterns when high resolution (smaller than $10 \mathrm{~nm}$ ) and high versatility are required. ${ }^{13}$ Our approach consists in replacing the usual resist layer by an opal film built of microspheres tailored in the same material. The photonic crystal structuring is schematically represented in Fig. 1. After the crystal is grown on the substrate in a vertical position, the structuring is a two-step process. First, the opal film is locally exposed to an electron beam, followed by a development in a solvent to remove selectively the exposed material.

In conventional EBL, the resist is usually deposited on the substrate as a very thin layer (typically below $300 \mathrm{~nm}$ ). In this nearly two-dimensional geometry, the processed material is basically defined by the area that has been exposed to the scanning electron beam. Since in the case of an opal film, the thickness is typically 5 to $10 \mu \mathrm{m}$, this description is no longer valid. In fact, the volume of processed material depends on the 3D distribution of the electrons within the film. Thus, by controlling the electron accelerating voltage $V_{\text {acc }}$ (i.e., the penetration depth of electrons), ${ }^{13}$ it becomes possible to control the depth of the written structure.

Thus, compared to other exposure parameters (magnification, spot size, step size, etc.), which affect the in-plane resolution and the writing time, $V_{\text {acc }}$ is the most relevant one for 3D structuring purposes. Several values were tested and the dependance upon $V_{\text {acc }}$ is plotted in Fig. 2. In order to have a working definition of lateral resolution in opal films, we have considered here the sharpness of the corners compared with the sphere diameters, expressed in radius of curvature. SEM micrographs of various structures obtained for different $V_{\text {acc }}$ are shown in Fig. 3. Although high $V_{\text {acc }}$ provide the best in-plane resolution, it is not possible to distinguish the bottom surface by SEM due to shadowing [Fig. 3(a)]. Optical microscopy observations (not presented here) show that the patterning becomes as deep as the film and the film itself is melted by the process. On the contrary, low $V_{\text {acc }}$ result in a very shallow depth of writing, but a worse lateral resolution [Fig. 3(c)]. With our material molecular weight,

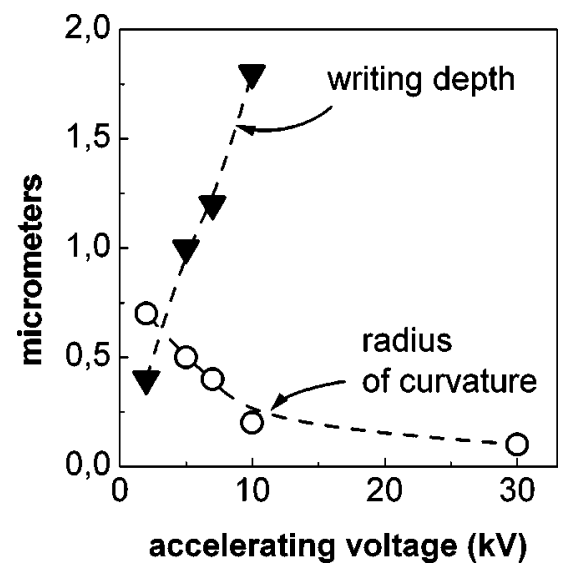

FIG. 2. Dependence of writing depth and lateral resolution upon the accelerating voltage $V_{\text {acc }}$. Dashed lines are guides for the eyes.

the best working conditions, which are the trade-off between writing depth and resolution, were found to be the 2 to $10 \mathrm{kV}$ range, giving rise to a range of controllable writing depths from 0.4 up to $2 \mu \mathrm{m}$.

The accuracy of the process can be evaluated in Fig. 3(b). The orientation of the rectangular structure matches the orientation of the $\mathrm{PhC}$ lattice. The sharpness of the edges as well as the small radius of curvature at the corners demonstrates that the lateral resolution is of the order of magnitude
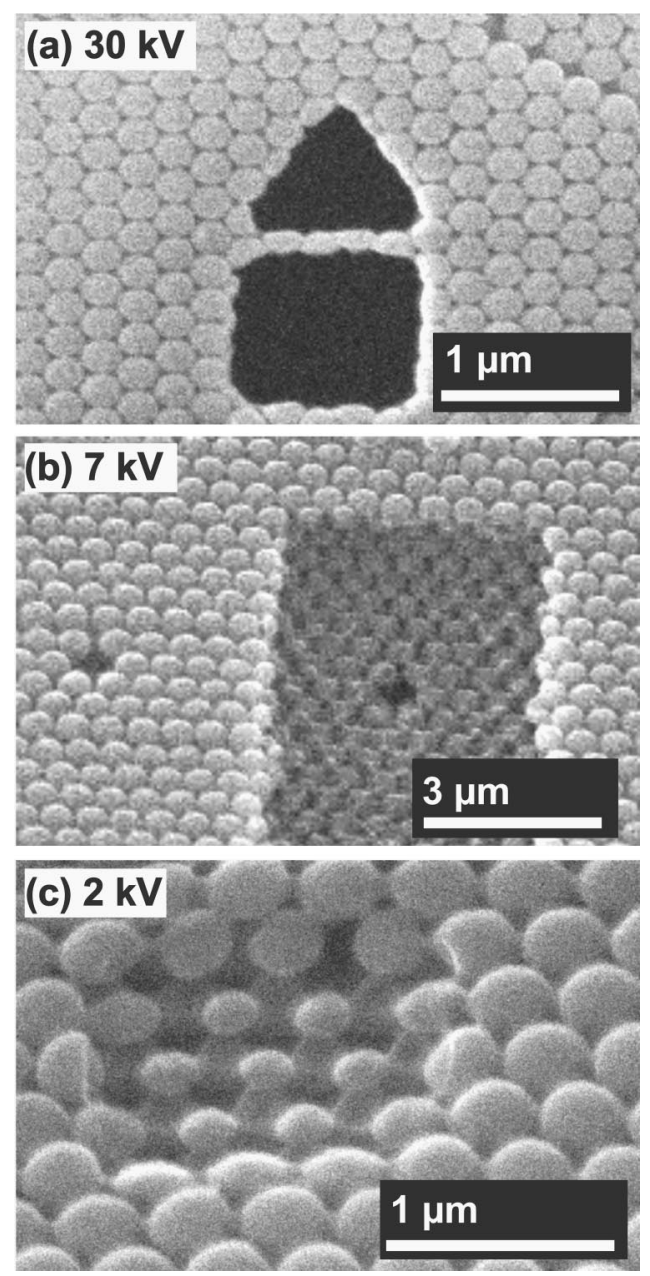

FIG. 3. SEM micrographs of intentional defects created in opal films, for different values of the accelerating voltage $V_{\text {acc }}$ : (a) $30 \mathrm{kV}$, (b) $7 \mathrm{kV}$, and (c) $2 \mathrm{kV}$. 
of one sphere diameter or better. The bottom surface of the structure is clearly flat on the scale of one sphere diameter, but it is covered by small particles. These are probably residues of incompletely dissolved spheres, indicating that the exposure parameters and that the developing conditions need better tuning. Nevertheless, in the present case, the remarkable size uniformity of these particles constitutes unambiguous evidence that the bottom surface of the cavity follows the $\mathrm{PhC}$ lattice.

As such, this technique allows the writing of structures with a size from a few spheres up to several $100 \mu \mathrm{m}$. We have shown that EBL affects preferably the upper layer of the opal film, however this technique could be extended towards the fabrication of deterministic buried defect structures, by taking advantage of two specific properties of opal films; namely, the possibility of growth interruption ${ }^{14}$ and the open porosity of the film. For example, buried defects could be fabricated by the following three-step process: (i) definition of defect structures by EBL, (ii) subsequent growth of another film on the first one, and (iii) development of the exposed and buried spheres, within reach of the developing solvent thanks to the porous nature of the material.

In addition, in order to fulfill the conditions for a complete photonic bandgap, the infilling of the opal structure with a high refractive index material is necessary. This issue has been addressed recently by several groups. In the case of a polymer template, various techniques, such as sol-gel hydrolysis, ${ }^{15}$ infilling with nanoparticles, ${ }^{16}$ or chemical vapor deposition. ${ }^{17}$ have been investigated. Although the filling factor $f$ still needs to be improved, results obtained using $\mathrm{TiO}_{2}$ ( $f$ up to $12 \%$ in Ref. 16 ) and $\mathrm{SnS}_{2}$ ( $f$ up to $14 \%$ in Ref. 17) are encouraging. ${ }^{18}$ This approach would offer a unique way to create genuine 3D optical microstructures, from highly confined 3D resonators to single-mode light guides.

In summary, a technique has been described that is capable of structuring 3D PhCs using EBL. We have shown that the control of the writing depth can be achieved by varying the electron acceleration voltage. Controlled structures with a depth from 0.4 up to $2 \mu \mathrm{m}$ have been fabricated with a typical lateral resolution of $0.4 \mu \mathrm{m}$. The relevance of this technique for the fabrication of deterministic defects in photonic crystals has been discussed, and its extension towards buried structures has been suggested.
The authors acknowledge the support of the German Research Council (DFG) Priority Program SPP 1113 "Photonic Crystals" and of the EU-IST Project PHOBOS Grant No. 19009.

${ }^{1}$ J. D. Joannopoulos, P. R. Villeneuve, and S. Fan, Nature (London) 386, 143 (1997).

${ }^{2}$ V. N. Astratov, V. M. Bogomolov, A. A. Kaplyanskii, A. V. Prokofiev, L. A. Samoilovich, S. M. Samoilovich, and Y. A. Vlasov, Nuovo Cimento D 17, 1349 (1995).

${ }^{3}$ F. Garcia Santamaria, H. T. Miyazaki, A. Urquia, M. Ibisate, M. Belmonte, N. Shinya, F. Meseguer, and C. Lopez, Adv. Mater. (Weinheim, Ger.) 14, 1144 (2002).

${ }^{4}$ S. Noda, K. Tomoda, N. Yamamoto, and A. Chutinan, Science 289, 604 (2000).

${ }^{5}$ S. M. Yang and G. A. Ozin, Chem. Commun. (Cambridge) 2000, 2507 (2000).

${ }^{6}$ P. Ferrand, M. Egen, B. Griesebock, J. Ahopelto, M. Müller, R. Zentel, S. G. Romanov, and C. M. Sotomayor Torres, Appl. Phys. Lett. 81, 2689 (2002).

${ }^{7}$ M. Bayindir, E. Ozbay, B. Temelkuran, M. M. Sigalas, C. M. Soukoulis, R. Biswas, and K. M. Ho, Phys. Rev. B 63, 081107 (2001); A. Chutinan, S. John, and O. Toader, Phys. Rev. Lett. 90, 123901 (2003).

${ }^{8}$ Y. A. Vlasov, X. Z. Bo, J. C. Sturm, and D. J. Norris, Nature (London) 414, 289 (2001).

${ }^{9}$ W. M. Lee, S. A. Pruzinsky, and P. V. Braun, Adv. Mater. (Weinheim, Ger.) 14, 271 (2002).

${ }^{10}$ B. H. Cumpston, S. P. Ananthavel, S. Barlow, D. L. Dyer, J. E. Ehrlich, L. L. Erskine, A. A. Heikal, S. M. Kuebler, I. Y. S. Lee, D. McCordMaughon, Q. Jinqui, H. Rockel, M. Rumi, W. Xiang Li, S. R. Marder, and J. W. Perry, Nature (London) 398, 51 (1999).

${ }^{11}$ M. Müller, R. Zentel, T. Maka, S. G. Romanov, and C. M. Sotomayor Torres, Chem. Mater. 12, 2508 (2000).

${ }^{12}$ Z. Z. Gu, A. Fujishima, and O. Sato, Chem. Mater. 14, 760 (2002).

${ }^{13}$ M. A. McCord, M. J. Rooks, in Handbook of Microlithography, Micromachining, and Microfabrication, edited by P. Rai-Choudhury (SPIE Optical Engineering Press, Bellingham, Washington, 1997), Vol. 1, p. 139.

${ }^{14}$ P. Jiang, G. N. Ostojic, R. Narat, D. M. Mittleman, and V. L. Colvin, Adv. Mater. (Weinheim, Ger.) 13, 389 (2001).

${ }^{15}$ G. Subramanian, K. Constant, R. Biswas, M. M. Sigalas, and K. M. Ho, Appl. Phys. Lett. 74, 3933 (1999).

${ }^{16}$ J. E. G. Wijnhoven, L. Bechger, and W. L. Vos, Chem. Mater. 13, 4486 (2001).

${ }^{17}$ M. Müller, R. Zentel, T. Maka, S. G. Romanov, and C. M. Sotomayor Torres, Adv. Mater. (Weinheim, Ger.) 12, 1499 (2000).

${ }^{18}$ Note that the volume fraction of voids for an ideal compact fcc packing is $f=26 \%$. 